\title{
DC Fault Protection Strategy Considering DC Network Partition
}

\author{
Md Habibur Rahman, Lie Xu \\ Department of Electronic \& Electrical Engineering \\ University of Strathclyde, Glasgow, United Kingdom \\ habibur.rahman@strath.ac.uk, lie.xu@strath.ac.uk
}

\author{
Liangzhong Yao \\ China Electric Power Research Institute \\ Xiaoying Road, Beijing, 100192, China \\ yaoliangzhong@epri.sgcc.com.cn
}

\begin{abstract}
This paper investigates DC network partition and alternative DC fault protection strategy for Multi-terminal HVDC (MTDC) system. Fast acting DC Circuit Breakers (DCCBs) or fault blocking DC-DC converters can be configured at strategic locations to allow the entire MTDC system to be operated interconnected but partitioned into islanded DC network zones following faults. In case of any DC fault event, the DCCBs or DC-DC converters at the strategic cable connections that link the different DC network partitions are opened or blocked such that the faulty DC network zone is quickly isolated from the remaining of the MTDC system. Thus, the healthy DC network zone can remain operational or recover quickly to restore power transmission. Each DC network zone can be protected using $\mathrm{AC}$ circuit breakers and DC switches for cost reduction. The validity of the proposed protection strategy is confirmed using MATLAB/SIMULINK simulations.
\end{abstract}

Index Terms-- DC fault, DC network partition, DC Circuit Breaker, Multi-terminal HVDC System.

\section{INTRODUCTION}

The increased global energy demands and the utilization of renewable energy generation have raised new requirements for the future electricity grid connection. The development of renewable energy and increasing the security of supply require large scale offshore and onshore network integration leading to transmit large amount of power over a long distance. HVDC becomes a more preferable choice in terms of transmitting a bulky amount of power over a long distance due to the transmission losses and smaller cable size for given power level when compared to traditional HVAC transmission system.

Multi-terminal HVDC system (MTDC) using VSC technology has greater flexibility for large-scale renewable energy integration and transmission network connection due to its ability for independent power control both active and reactive power, AC voltage support, and black-start capabilities. However, there is a major challenge toward the protection of an MTDC system in the event of a fault at the DC side of the network including fault protection, fault location and isolation[1-3]. As the rate of rise of DC fault current is very high due to the low impedance of the DC network, the protection system has to act fast and an effective protection method needs to detect the fault and its location and isolate the faulty line in a selective manner allowing fast restoration of normal system operation following a DC fault[3-6].

There are several protection methods that have been proposed for MTDC system[3-7]. A protection method of VSC based MTDC system was discussed in [7] in which a 'Handshaking' method using AC circuit breakers and DC switchgear were proposed. But the system recovery is slow which can pose significant operational problems for large scale MTDC systems and connected AC networks due to the loss of the entire network. Fast acting DCCB which is capable of operating within a few milliseconds can be adopted to isolate the faulty cable such that the healthy part of the DC network can continue operating or quickly recover. However, such DCCBs are likely to have high capital cost, larger footprint and high on state losses, and thus, their use should be limited. Introducing MMC based DC-DC converter into a MTDC system in terms of protection can bring significant benefit to the entire system. There are many DC-DC converter configuration have been proposed [8-11] for MTDC system. The main advantages of using DC-DC converters are their ability to connect DC networks of different voltage levels and control the power flow, isolate the fault quickly etc. In case of any fault event the DC-DC converter rapidly isolates the faulty section such that the healthy part of the system remains operational and unaffected.

In this paper, different MTDC system configurations are analysed in terms of DC fault protection considering the minimal use of DCCBs or DC-DC converter at strategic locations to allow the entire MTDC system to be operated interconnected but partitioned into islanded DC network zones following faults. The paper is structured as follows: Section II describes the fault behaviour of an MMC based converter. DC network configuration and different protection options are outlined in section III and the simulation studies of the proposed concept are presented in section IV and section $\mathrm{V}$ draws the conclusions.

\section{DC FAULT BEHAVIOUR}

DC faults can cause serious consequences due to the low impedance of the DC network and the existence of the freewheeling diodes in half-bridge MMC converters in HVDC system[12-14]. The simplified equivalent circuit of a 
half bridge MMC during a DC line-to-line fault is shown in Fig. 1. Unlike the two-level VSC, MMC does not have a large DC link capacitor at converter terminal though cable capacitor is still present.

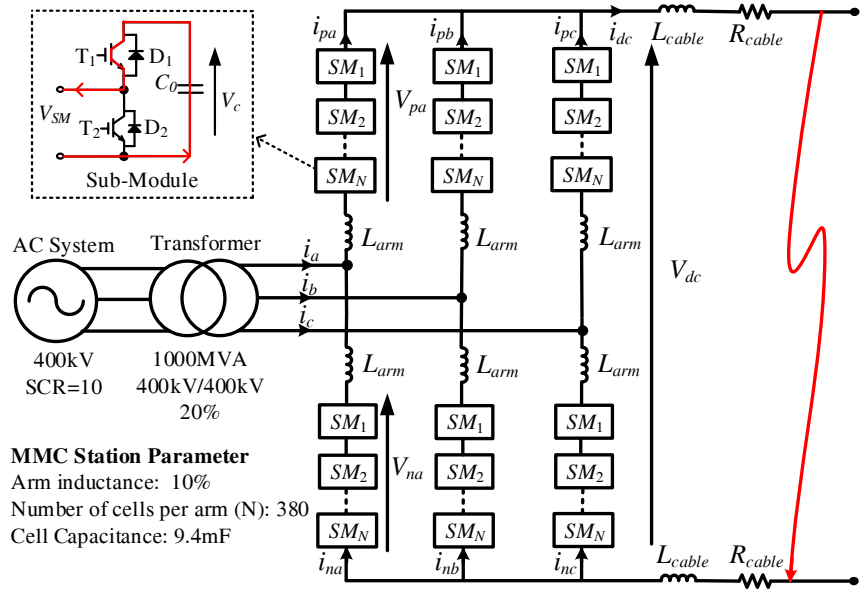

Fig. 1. Equivalent circuits of half bridge MMC during DC line-to-line fault
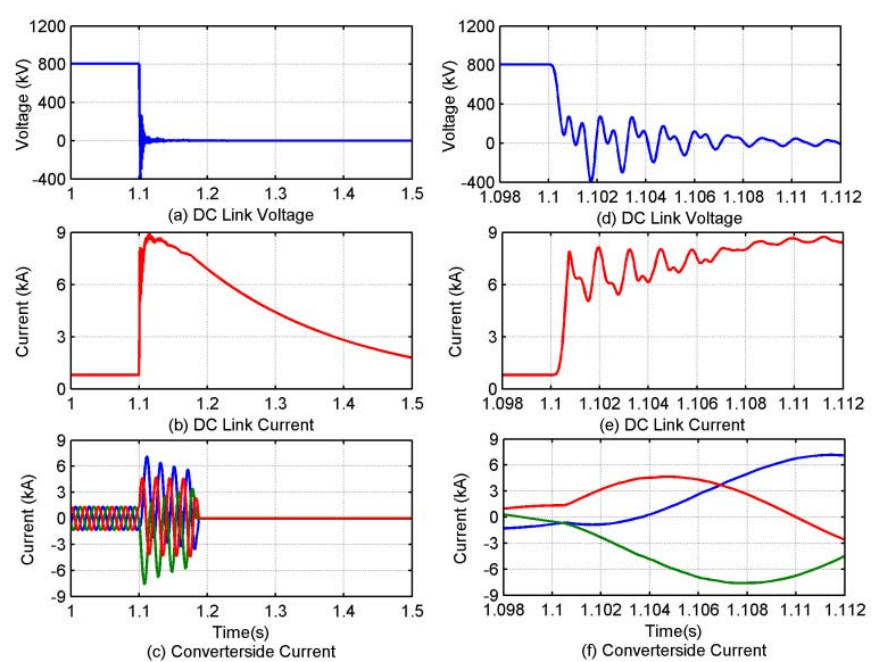

Fig. 2. DC current and voltage of MMC during DC line-to-line fault

A typical half-bridge MMC based converter has been considered for analysing the DC fault behaviour. A permanent DC line-to-line fault is applied at 1.1s and the MMC based converter is blocked $1 \mathrm{~ms}$ after the fault initiation. Fig. 2 shows the system response during the whole fault period. Long (Figs. 2(a)-(c)) and short (Figs. 2(d)-(f)) duration time-scale waveforms have been presented for ease of analysis. Figs. 2(a) and (d) show the collapse of the converter DC link voltage with oscillations immediately after fault initiation. Due to the arm reactance the DC link voltage can reach to a negative value. Figs. 2(b) and (e) represent the converter DC currents showing rapid increase after fault initiation. As the MMC converter behaves as an uncontrolled rectifier after IGBT blocking, the DC link current cannot decay to zero until AC circuit breaker is opened. In this simulation the tripping time of the AC circuit breaker is set to be $80 \mathrm{~ms}$ after the converter arm current is detected. Until open AC circuit breaker the arms current have to withstand huge over current. Figs. 2(c), and (f) shows large AC currents during DC fault which are flowing through the anti-parallel diodes.

\section{DC NETWORK PARTITION AND DIFFERENT PROTECTION OPTIONS}

\section{A. DC Network Partition}

One of the main concerns for large scale MTDC system is the potential loose of power transmission across the entire network in the event of a single fault on part of the DC network. This issue can be partially mitigated by installing fast acting DCCBs at every DC line connection points though with large increase of system cost. The infrequency of DC fault events and the inconsistency of power generation from wind farms, the expected cost of losing access to that energy may not be sufficient to justify huge investment in protection cost. To justify the cost and reliable protection, the entire MTDC system can be configured in a number of partitions (like different DC network zones within the MTDC system) where a fault anywhere on a particular partition would result in the partition being isolated by clearance from "slow" DC switches and circuit breakers on the AC side[15] .

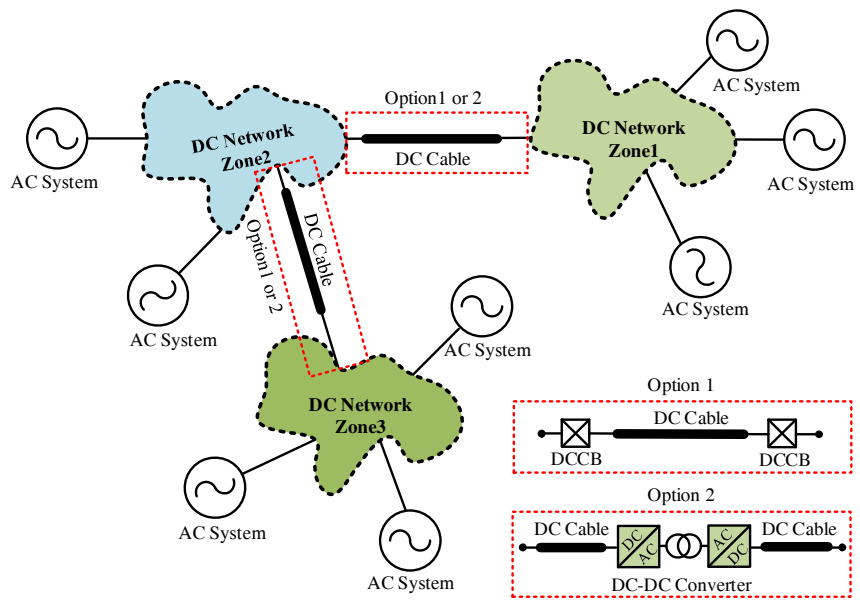

Fig. 3. Possible DC network partition using least number of DCCBs or DCDC converter

In the event of a DC fault it is required from system operators' point of view to keep the permanent 'loss of infeed' below the maximum power loss criterion (e.g. $1.32 \mathrm{GW}$, as is the present case in GB) to maintain system stability. Therefore, the partitioning of the MTDC system should be configured in such a way that the power generation export from offshore is maximised in the event of fault. The power being supplied from any partition (any DC network zone) to any $\mathrm{AC}$ system to which it is connected is less than the limit for a permanent 'loss of infeed' limit of that AC system[15]. However, such partitioning reduces the operational flexibility of the MTDC system. The aforementioned DC network partitioning can be more optimised by placing fast acting DCCBs or DC-DC converter at strategic location connecting different DC network zones to allow the entire MTDC system to be operated interconnected pre-fault but partitioned into islanded sections (DC network zones) following faults. A typical DC network configuration is shown in Fig. 3 where only limited numbers of fast acting DCCBs or DC-DC converters are used to reduce the capital cost of the entire MTDC system. In case of any fault event within one DC network zone at least two of the DC network zones can be 
remain operational or restored quickly after isolating the faulty zone depending on the fault location.

\section{B. Protection Option}

There are a few possible options to clear the DC side faults without causing a large loss of infeed. Different protection strategies for MTDC system have been described and analysed in[3-11, 16-18]. The main purpose of this work, in case of any fault event in one DC network zone, the healthy zone can be continued operational or will achieve normal operation after isolating faulty zones by means of using the equipped DCCBs or DC-DC converter. The faulty DC network zone can be protected using AC circuit breakers and DC switches. The following steps have been taken for the proposed system to clear a DC fault.

1. Using local current measurement to detect the fault current flowing through DCCBs and converter arms.

2. If the fault current goes above pre-determined set value the fast acting DCCBs will be set to open (with a $5 \mathrm{~ms}$ delay for this study). In addition, a converter will be blocked if its arm current reaches its threshold protective level.

3. After isolating the faulty zone the system may require to restart for the normal operation depending on fault location.

4. The faulty DC network zone can be protected using ACCBs.

\section{SIMULATION STUDIES}

Fig. 4 shows the five-terminal MTDC system considered in the paper consisting of MMC based converter connected to AC systems. The system contains two DC network zones which are interconnected by DC cables equipped with fast acting DCCBs or DC-DC converters. No DCCBs are used within each DC network zone so as to minimise the cost and power loss. Within each zone, the DC network zone is protected using slow AC circuit breakers and DC switches. The proposed two protection options, i.e. one uses DCCBs and the other uses DC-DC converters, are applied to the MTDC system shown in Fig. 4 and simulated using MATLABSIMULINK. Modelling an MMC converter in detail switching mode requires large computational efforts, thus, average models with controllable voltage and current sources are used, and additional semiconductor devices are added to ensure that the model accurately replicates all possible current paths in a real converter during DC faults. On this configuration $\pi$ model of the cable is used.

The Station 1 and 3 are assigned to transmit 800MW and $600 \mathrm{MW}$ power to the DC grid, respectively. Station 5 transmits 300MW power to the AC grid whereas Station 2 and 4 regulate the DC link voltage $(800 \mathrm{kV}$ for Option 1 and for Option 2, Zone 1 and Zone 2 DC link Voltages are 640kV and $800 \mathrm{kV}$ respectively ) of the entire MTDC system using DC droop control to ensure effective active power sharing between the two. For option 2 DC-DC converter's Station B is designed to transmit $200 \mathrm{MW}$ power from Zone 1 to Zone 2 while Station A is set for controlling the internal AC source. For simplicity, each converter operates at unity power factor. A DC line-to-line fault is applied at the midpoint of the transmission line between Station 1 and 2 which is $50 \mathrm{~km}$ away from both stations at 2.1s.

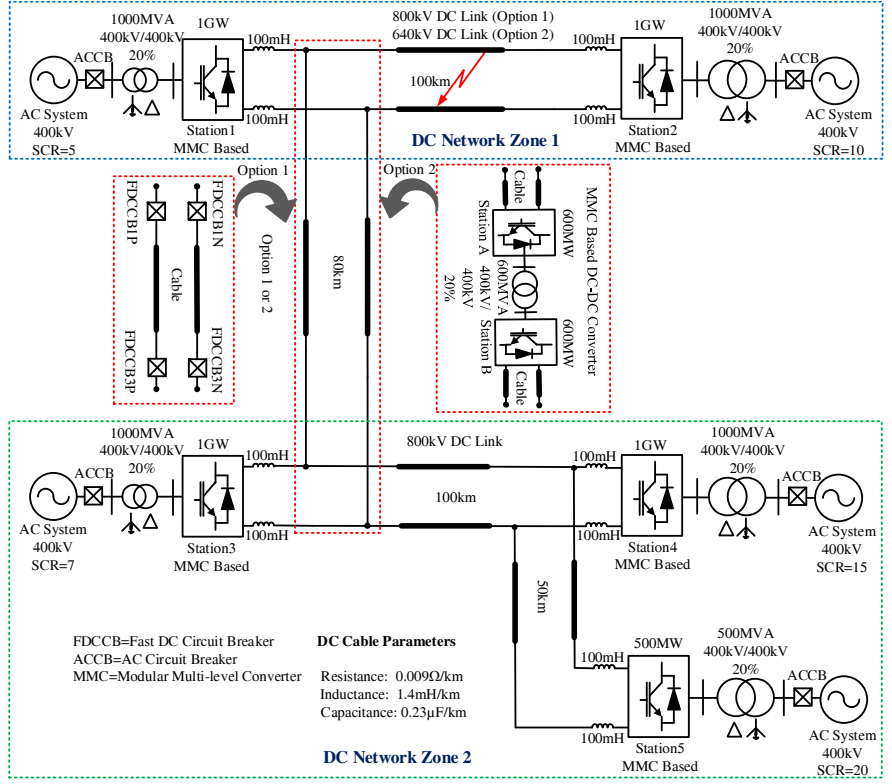

Fig. 4. Block diagram of a proposed five terminal MMC based MTDC system

\section{A. Case Study 1 - Option1 (DCCBs)}

The obtained results representing the system's behaviour are presented in Figs. 5(a)-(e), where the responses of the DC voltage magnitudes (as recorded on the DC Link voltage of each converter) to the fault are shown.
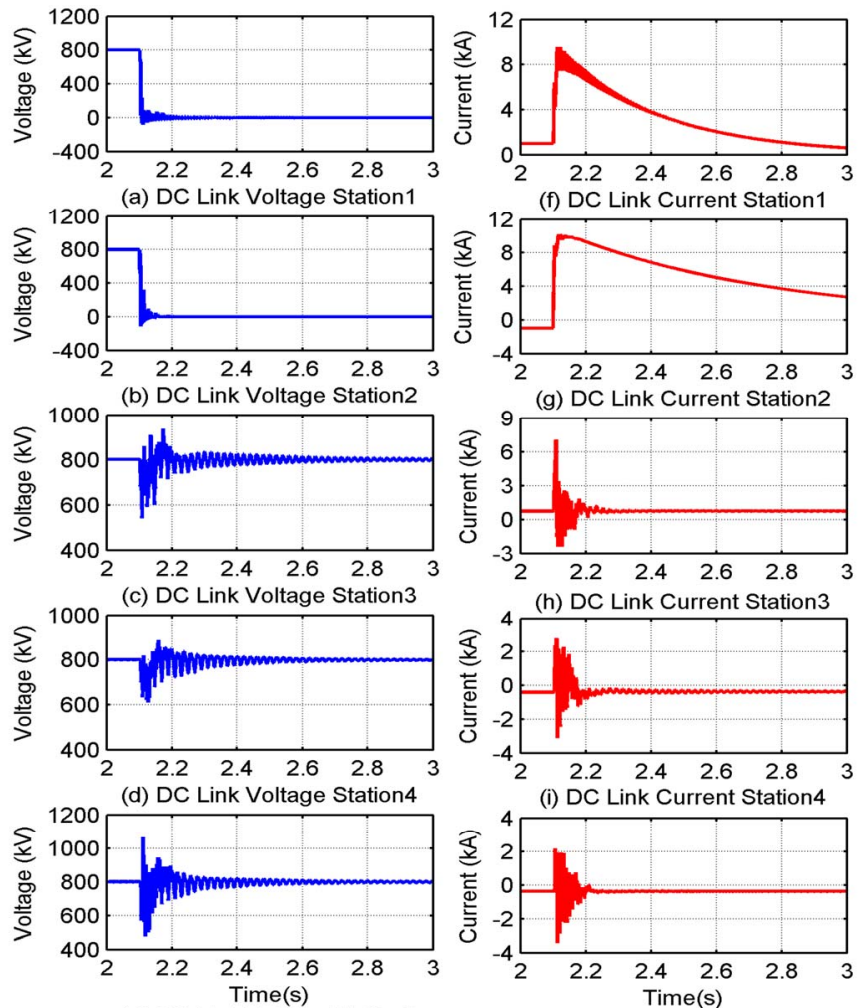

(e) DC Link Voltage Station5

(j) DC Link Current Station5

Fig. 5. System behaviour on the DC side during a DC fault at 2.1s 
It is evident from Fig. 5, that the DC fault has severe impacts on the entire MTDC system which lead to DC voltages collapse and increase in DC link current. The DC link voltages on each side of the faulty line decrease faster than the other DC link voltages. Figs. 5(f)-(j) demonstrate the DC link current during the fault. It can be seen that the fault peak current is higher in Station 1 and 2 compare to others due to the distance of the fault location.

Fig. 6 represents the upper arm currents and converter-side AC currents respectively. Converter blocking is activated when the measured arm currents exceed the pre-determined set value. In this simulation study Station 1 and 2 are blocked $4 \mathrm{~ms}$ after the fault initiation while converter stations 3-5 remain operational. After blocking the converter Station 1 and 2, the AC currents continue increasing (see Figs. 6(f) and (g)) through the freewheeling diodes.
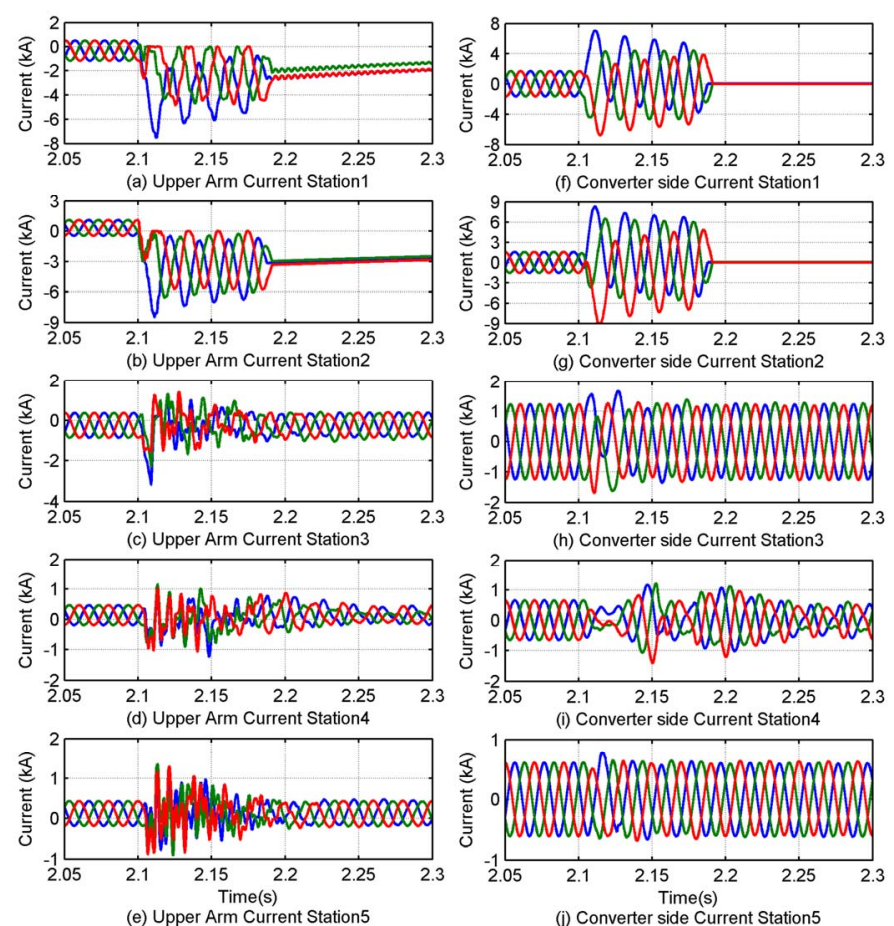

Fig. 6. Upper arm and converter-side AC currents during a DC fault at $2.1 \mathrm{~s}$

In this simulation FDCCB1P and FDCCB1N are opened $7 \mathrm{~ms}$ after fault initiation (2ms detection time plus $5 \mathrm{~ms}$ opening delay) whereas for FDCCB3P and FDCCB3N, it is $9 \mathrm{~ms}$. After the opening of the fast acting DCCBs, the complete MTDC system is split into two isolated DC network zones. For the faulty Zone 1, the AC circuit breakers of Station 1 and 2 opens around $84 \mathrm{~ms}$ after the fault initiation, and the AC current, the arm current and the DC currents gradually then decay to zero. For DC Zone 2, all the converters remain operational during the fault period though with some fluctuations in DC voltages, DC link currents, arm and AC currents. (See Figs. 5 and 6). Despite this fact, all currents and voltages of the DC Zone 2 remain within acceptable tolerance band. Power transmission continues in DC Zone 2 though power flow was automatically altered due to the removing of the interconnection between Zone 1 and 2 .

\section{B. Case Study 2 - Option 2 (DC-DC Converter)}

The main concept of this protection arrangement is that, in case of any fault events in one DC zone, the DC-DC converter can quickly isolate the faulty zone by blocking its converter such that the healthy zone can remain operational all the times.

The obtained results representing the system's behaviour are presented in Figs. 7 and Fig. 8. It is evident from Fig. 7, that the DC fault severely affects the DC voltage in Zone 1 and results in the rapid increase in the DC link current. The DC over current flowing through the DC-DC converter is quickly detected which results in the immediate block of the DC-DC converter. This effectively isolate Zone 1 from the healthy Zone 2 and it can be seen that there is little impact on the DC voltages and currents in Zone 2 due to the fast blocking of the DC-DC converter.

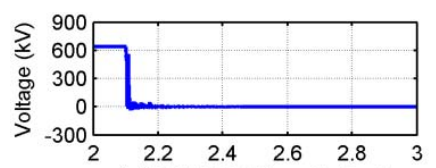

(a) DC Link Voltage Station1
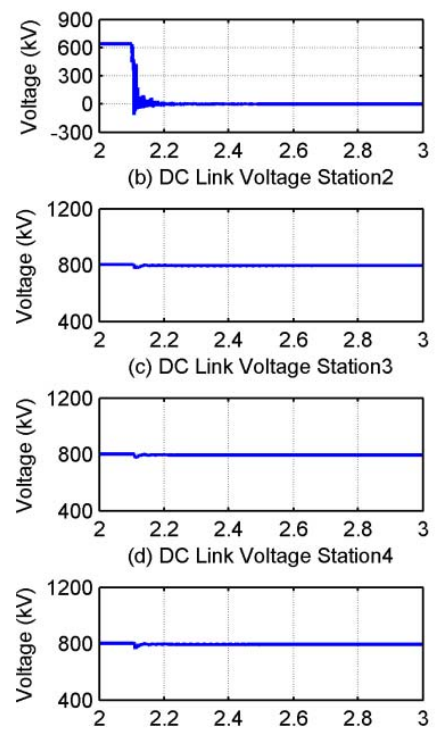

(e) DC Link Voltage Station5
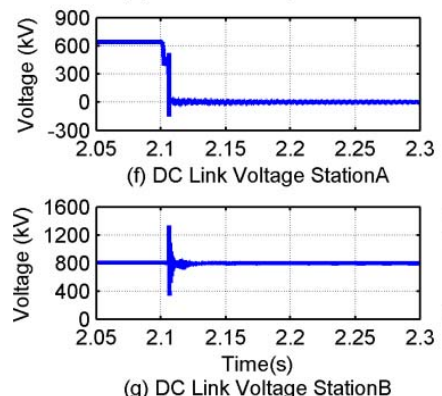

(g) DC Link Voltage StationB

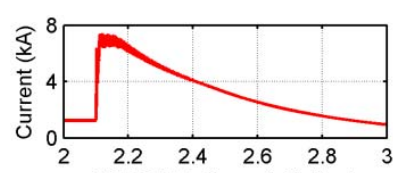

(h) DC Link Current Station1

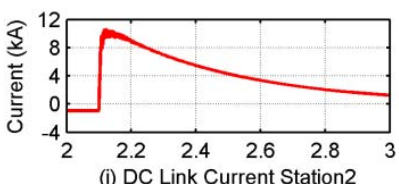

(i) DC Link Current Station2
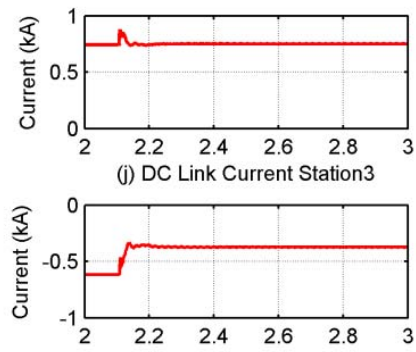

(k) DC Link Current Station4

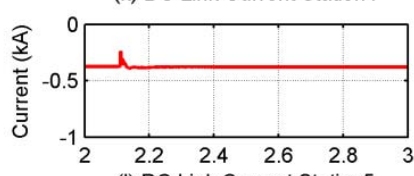

(I) DC Link Current Station
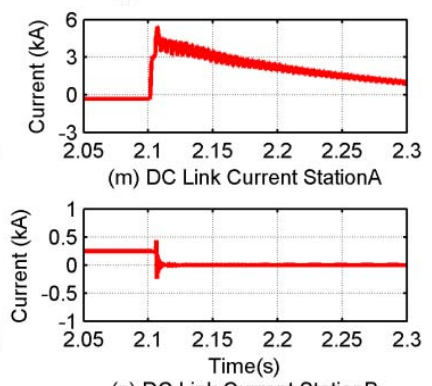

(n) DC Link Current StationB

Fig. 7. System behaviour on the DC side during a DC fault at $2.1 \mathrm{~s}$

Fig. 8 represents the upper and converter-side AC currents respectively. In this proposed system as soon as a fault occurs, only the converters located in Zone 1 and DC-DC converter stations have been blocked in a selective manner using automatic detection and blocking method. In this simulation study Station 1, 2 and DC-DC converter stations are blocked 
their converters at $3 \mathrm{~ms}, 7 \mathrm{~ms}$ and $6 \mathrm{~ms}$ respectively after the fault initiation. After blocking the converter, the AC current continue increasing (see Fig. 8 (h) and (i)) through the freewheeling diodes. Here DC Zone 1 is protected using AC circuit breakers. In this simulation study AC circuit breakers equipped in Station 1 and 2 are opened at $83 \mathrm{~ms}$ and $87 \mathrm{~ms}$ respectively, after the fault initiation.

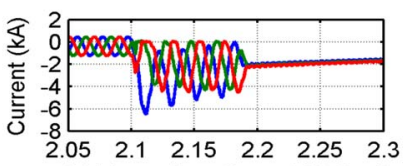

(a) Upper Arm Current Station1

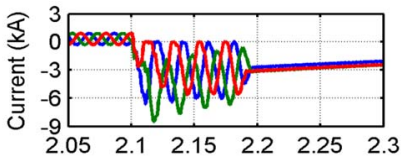

(b) Upper Arm Current Station2

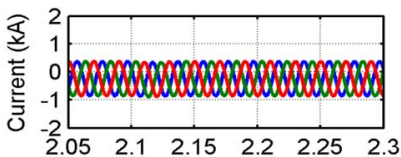

(c) Upper Arm Current Station3

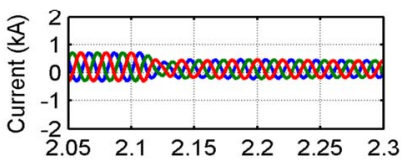

(d) Upper Arm Current Station4

(e) Upper Arm Current Station5

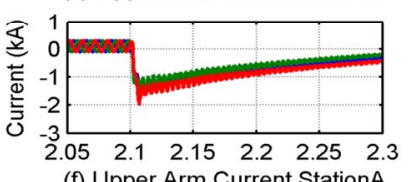

(f) Upper Arm Current StationA

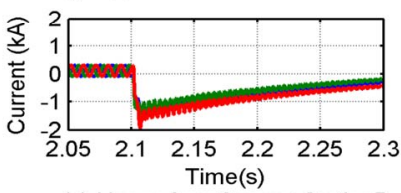

(g) Upper Arm Current StationB

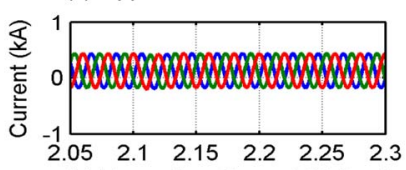

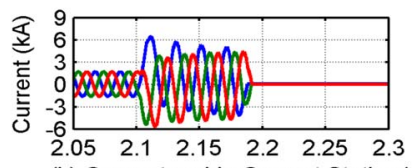
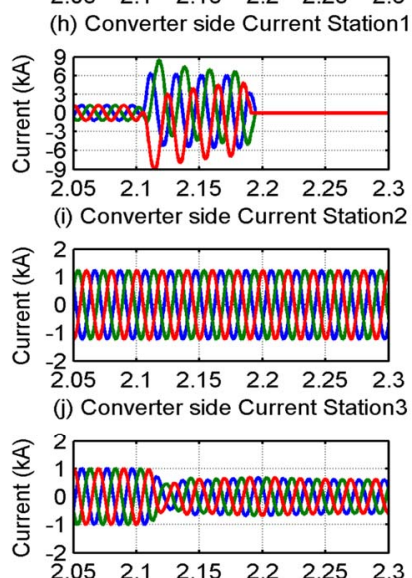

(k) Converter side Current Station 4

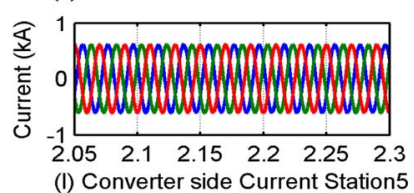

Converter side Current Station5

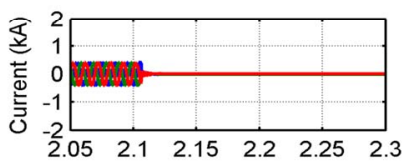

(m) Converter side Current Station

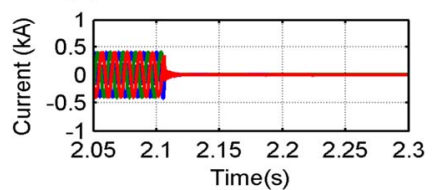

(n) Converter side Current StationB
Fig. 8. Arm currents and converter-side AC currents during a DC fault at 2.1s

\section{CONCLUSIONS}

DC network partition with minimum use of fast acting DCCBs or a DC-DC converter at strategic locations of the entire MTDC system are proposed and studied in this paper. The main purpose of the protection options is to isolate DC faults, without risking the continued operation of the healthy part of the entire MTDC system. The simulation results corresponding to DC fault protection have been presented give a satisfactory result. The proposed concept based on a five terminal MTDC system have been studied here, can be extended to different terminal numbers and DC network partitions which could be cost effective.

\section{REFERENCES}

[1] E. Kontos, R. T. Pinto, S. Rodrigues, and P. Bauer, "Impact of HVDC Transmission System Topology on Multiterminal DC Network Faults," IEEE Trans. on Power Delivery, vol. PP, pp. 1-1, 2014.

[2] N. Yousefpoor, S. Kim, and S. Bhattacharya, "Control of voltage source converter based multi-terminal DC grid under DC fault operating condition," in Energy Conversion Congress and Exposition (ECCE), 2014 IEEE, 2014, pp. 5703-5708.

[3] L. Tang and B.-T. Ooi, "Protection of VSC-multi-terminal HVDC against DC faults," in Power Electronics Specialists Conference, 2002. pesc 02. 2002 IEEE 33rd Annual, 2002, pp. 719-724 vol.2.

[4] W. Lu and B.-T. Ooi, "DC overvoltage control during loss of converter in multiterminal voltage-source converter-based HVDC (MVSC-HVDC)," IEEE Trans. on Power Delivery,, vol. 18, pp. 915-920, 2003.

[5] J. Yang, J. E. Fletcher, and J. O'Reilly, "Multiterminal DC Wind Farm Collection Grid Internal Fault Analysis and Protection Design," IEEE Trans. on Power Delivery, vol. 25, pp. 2308-2318, 2010.

[6] H. Liu, Z. Xu, and Y. Huang, "Study of protection strategy for VSC based HVDC system," in Transmission and Distribution Conference and Exposition, 2003 IEEE PES, 2003, pp. 49-54 Vol.1.

[7] L. Tang and B.-T. Ooi, "Locating and Isolating DC Faults in MultiTerminal DC Systems," IEEE Trans. on Power Delivery, vol. 22, pp. 1877-1884, 2007.

[8] M. Hajian, D. Jovcic, and W. Bin, "Evaluation of Semiconductor Based Methods for Fault Isolation on High Voltage DC Grids," IEEE Trans. on Smart Grid, vol. 4, pp. 1171-1179, 2013.

[9] R. Zeng, L. Xu, and Y. Liangzhong, "DC/DC Converters Based on Hybrid MMC for HVDC Grid Interconnection," in AC and DC Power Transmission, 11th IET International Conference on, 2015, pp. 1-6.

[10] I. A. Gowaid, G. P. Adam, A. M. Massoud, S. Ahmed, D. Holliday, and B. W. Williams, "Quasi Two-Level Operation of Modular Multilevel Converter for Use in a High-Power DC Transformer With DC Fault Isolation Capability," IEEE Trans. on Power Electronics, vol. 30, pp. 108-123, 2015.

[11] D. Jovcic, M. Taherbaneh, J. P. Taisne, and S. Nguefeu, "Developing regional, radial DC grids and their interconnection into large DC grids," in PES General Meeting Conference \& Exposition, 2014 IEEE, 2014, pp. 1-5.

[12] Y. Gao, M. Bazargan, L. Xu, and W. Liang, "DC fault analysis of MMC based HVDC system for large offshore wind farm integration," in Renewable Power Generation Conference (RPG 2013), 2nd IET, 2013, pp. 1-4.

[13] J. Rafferty, L. Xu, and D. J. Morrow, "DC fault analysis of VSC based multi-terminal HVDC systems," in $A C$ and DC Power Transmission (ACDC 2012), 10th IET International Conference on, 2012, pp. 1-6.

[14] J. Rafferty, L. Xu, and J. Morrow, "Analysis of voltage source converter-based high-voltage direct current under DC line-to-earth fault," Power Electronics, IET, vol. 8, pp. 428-438, 2015.

[15] K. R. W. Bell, L. Xu, and T. Houghton, "Considerations in design of an offshore network," in CIGRE Science \& Engineering, Feb 2015, pp. 79-92.

[16] W. Ahmed and P. Manohar, "DC line protection for VSC-HVDC system," in Power Electronics, Drives and Energy Systems (PEDES), 2012 IEEE International Conference on, 2012, pp. 1-6.

[17] C. D. Barker and R. S. Whitehouse, "An alternative approach to HVDC grid protection," in $A C$ and DC Power Transmission (ACDC 2012), 10th IET International Conference on, 2012, pp. 1-6.

[18] F. Page, S. Finney, and L. Xu, "An alternative protection strategy for multi-terminal HVDC," in 13th Wind Integration Workshop, Berlin, Nov.2014. 